\title{
Endocarditis in intravenous drug abusers with staphylococcal septicaemia
}

\author{
JENNIFER M A BURNS, K J HOGG, W S HILLIS, F G DUNN \\ From the Departments of Cardiology and Materia Medica, Stobhill General Hospital, Glasgow
}

SUMMARY The case reports of 186 intravenous drug abusers admitted over a three year period were studied. Nineteen had proven staphylococcal septicaemia. Echocardiography showed tricuspid vegetations in seven and aortic vegetations in two. Eighteen out of 19 had systolic murmurs, but only the two patients with aortic vegetations had diastolic murmurs. The chest $x$ ray showed opacities in 10 patients (all those with tricuspid vegetations plus three with normal of echocardiograms). Four patients died during follow up, including both those with aortic 의 vegetations; both mitral and tricuspid vegetations were found at necropsy in the other two. All remaining patients were alive at one year.

The presence of tricuspid vegetations in intravenous drug abusers is associated with opacities on chest $x$ ray, but carries a good short term prognosis. But these results suggest a poor outcome when left sided endocarditis is present in intravenous drug abusers.

Endocarditis is a well recognised complication in heroin addicts who use the intravenous route. Such endocarditis may be difficult to distinguish from staphylococcal septicaemia without cardiac involvement. We have assessed the relative merits of clinical and investigative techniques in the cardiac assessment of intravenous drug abusers with documented staphylococcal septicaemia.

\section{Patients and methods}

In a retrospective review of case records for the years 1984-1986 inclusive, we found 186 admissions of intravenous drug abusers to Stobhill General Hospital, Glasgow, and to the local infectious diseases hospital, Ruchill Hospital. Of these, 19 had proven staphylococcal septicaemia. The mean age of these 15 men and four women was 24 (range 18-35). All 19 had had echocardiographic studies by $M$ mode and cross sectional techniques. These studies were reviewed by two independent observers who were asked to comment on the presence or absence of valve vegetations. A vegetation was defined as a nonuniform "shaggy" echogenic mass attached to the valve leaflet (figure). These findings were compared

Requests for reprints to Dr F G Dunn, Department of Cardiology, Stobhill General Hospital, Glasgow G21 3UW.

Accepted for publication 10 January 1989 with the clinical condition, chest $x$ ray findings, and outcome in each patient (table).

\section{Results}

Ten of the 19 patients had a normal echocardiogram. Seven had tricuspid vegetations and two had aortic vegetations. A review of the case notes showed that 18 of the 19 patients were reported to have a systolic murmur. Two patients had diastolic murmurs and both of them had aortic vegetations.

When the chest $x$ rays were reviewed, opacities suggestive of septic pulmonary emboli were found in seven patients with tricuspid vegetations and three with normal echocardiograms. None of the remaining patients, including those with aortic vegetations, $\frac{D}{2}$ had abnormal lung fields.

The outcome of the patients was assessed. All 10 of $\mathrm{N}$ those patients with a normal echocardiogram left $N$ hospital after an apparent recovery, although further N follow up found that one died over a year later after $\frac{\omega}{\sigma}$ operation for endocarditis of the mitral and tricuspid valves. Follow up was for a minimum of 18 months.

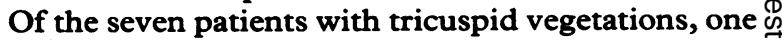
died on his first hospital admission. At necropsy he too was found to have mitral valve endocarditis in addition to tricuspid valve disease. Both patients $\underset{\mathbb{Q}}{\mathbb{Q}}$ with aortic valve disease died, although not on their $\overrightarrow{\mathbb{D}}$ first hospital admission. The cause of death in one $\frac{\varrho}{\sigma}$ was cardiac failure with pulmonary emboli. At 
Table Findings and outcome in 19 intravenous drug abusers with staphylococcal septicaemia

\begin{tabular}{|c|c|c|c|c|c|}
\hline & $\begin{array}{c}\text { Patients } \\
(n=19)\end{array}$ & $\begin{array}{l}\text { Systolic } \\
\text { murmur }\end{array}$ & $\begin{array}{l}\text { Diastolic } \\
\text { murmur }\end{array}$ & $\begin{array}{l}\text { Chest } \\
x \text { ray } \\
\text { opacities }\end{array}$ & Deaths \\
\hline $\begin{array}{l}\text { Normal echocardiogram } \\
\text { Tricuspid vegetations } \\
\text { Aortic vegetations }\end{array}$ & $\begin{array}{r}10 \\
7 \\
2\end{array}$ & $\begin{array}{r}10 \\
7 \\
1\end{array}$ & $\begin{array}{l}0 \\
0 \\
2\end{array}$ & $\begin{array}{l}3 \\
7 \\
0\end{array}$ & $\begin{array}{l}1 \\
1 \\
2\end{array}$ \\
\hline
\end{tabular}

necropsy his aortic valve was found to be bicuspid. The other patient died suddenly.

\section{Discussion}

Staphylococcal septicaemia is a well recognised sequela of intravenous drug abuse ${ }^{1}$ but it may be difficult to determine whether this is complicated by infective endocarditis. We found that systolic murmurs were unhelpful in establishing the diagnosis of endocarditis; both patients with aortic vegetations had diastolic murmurs, however. Clearly, the demonstration of vegetations by echocardiography confirms the diagnosis of endocarditis, but echocardiography may give false negative results. ${ }^{2}$ We found that all seven patients with tricuspid vegetations had opacities on chest $x$ ray but only three out of 10 patients with normal echocardiograms did. We therefore believe that if opacities are seen on the chest $x$ ray, serial echocardiograms should be obtained and the patient should be treated as for endocarditis. It has previously been suggested that the triad of intravenous drug addiction, staphylococcal septicaemia, and pulmonary embolism is pathognomic for tricuspid valve endocarditis. ${ }^{3}$

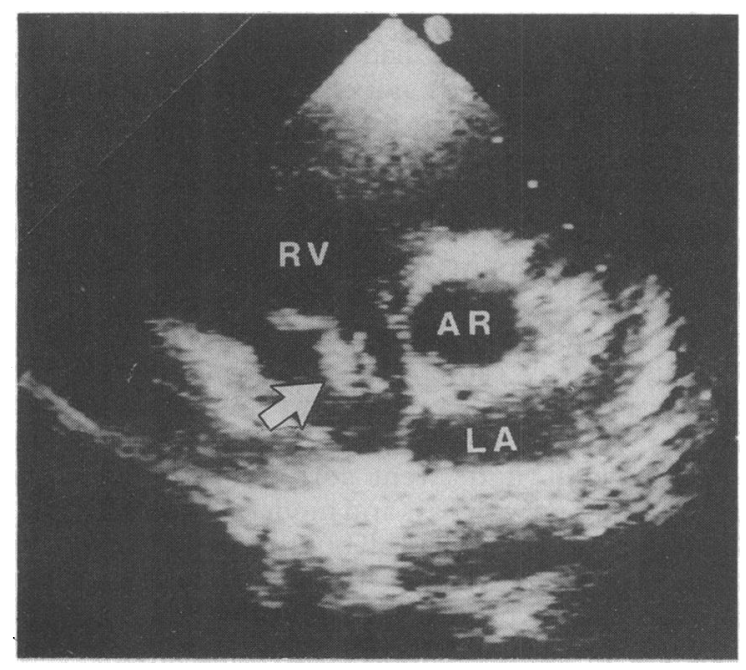

Figure A parasternal short axis cross sectional echocardiogram. Arrow indicates the tricuspid vegetation. $R V$, right ventricle; $A R$, aortic root; $L A$, left atrium.
The tricuspid vegetations were well toleratedthere were no early deaths in patients with isolated tricuspid vegetations. Follow up of these patients is difficult, but four of the six survivors with tricuspid vegetations have had repeat echocardiography, on average 18 months later. In all the vegetations had disappeared, but the tricuspid valve appeared thickened. Only one patient had clinical signs of mild right heart failure and tricuspid incompetence. Since the formal study has ended, a further three patients have been seen with the triad of staphylococcal septicaemia, pulmonary opacities, and tricuspid vegetations, and have all survived without sequelae.

In contrast, we confirmed the poor prognosis in those with left sided endocarditis. ${ }^{1}$ We have now seen four such patients, none of whom has survived more than a year after the diagnosis was made. We do not believe that operation is an option in these patients unless there is clear evidence that they have overcome their addiction.

Echocardiography is of unquestionable value in the diagnosis of endocarditis in intravenous drug abusers. Tricuspid endocarditis should be strongly considered as a diagnosis in staphylococcal septicaemia if there are opacities on chest $x$ ray, even when the echocardiogram is normal. The prognosis in left sided endocarditis is poor, whereas patients seem to tolerate the presence of tricuspid vegetations, at least in the short term.

\section{References}

1 Espersen F, Frimodt-Moller N. Staphylococcal aureus endocarditis: a review of 119 cases. Arch Intern Med 1986;146:1118-21.

2 Come PC, Isaacs RE, Riley MF. Diagnostic accuracy of $M$-mode echocardiography in acute endocarditis and prognostic implications of ultrasound vegetations. Am Heart J 1982;103/5:839-41.

3 Julander I, Arneborn P, Back E, Hoglund C, Svanbom M. Intravenous drug addiction-staphylococcal septicaemia-pulmonary embolism: a triad pathognomic for tricuspid valve endocarditis? Scand $J$ Infect Dis 1983;15:257-65. 